\title{
PENERAPAN APLIKASI DIAGNOSA PENYAKIT JANTUNG MENGGUNAKAN ALGORITMA FORWARD CHAINING BERBASIS MOBILE
}

\author{
Tri Sugihartono ${ }^{1}$, Rendy Rian Chrisna Putra ${ }^{2}$,Dian Ardiansyah ${ }^{3}$ \\ ${ }^{123}$ Jurusan Teknik Informatika, STMIK Atma Luhur Pangkalpinang \\ Jl. Jendral Sudirman, Kel. Selindung Baru, Kec. Pangkal Balam \\ Pangkal Pinang, Kepulauan Bangka Belitung \\ e-mail : trisugihartono@atmaluhur.ac.id
}

\begin{abstract}
Heart disease ranks the top cause of death compared to stroke, lung cancer, breast cancer, and AIDS. Most ordinary people are very concerned about health, especially heart health. They are reluctant to check their heart health due to lack of service to patients, lack of medical personnel, especially cardiologists and limited working hours of doctors. So the need for a technology that is capable of adopting human thinking is artificial intelligence technology. Expert system is one of the artificial intelligence technologies. This expert system was created as a means to help diagnose and manage patients. The development of this system uses the forward chaining and certainty factor algorithms, and the system development tools used are UML (Unified Modeling Language), this research will produce an expert system application to diagnose heart disease with the output of possible diseases along with the percentage. It is hoped that this expert system will help and accelerate the work of cardiologists in diagnosing early heart disease.
\end{abstract}

Keywords - heart disease, forward chaining, Unified Modeling Language, expert systems, diagnosis

\begin{abstract}
ABSTRAK
Penyakit jantung menduduki peringkat teratas penyebab kematian dibandingkan stroke, kanker paru-paru, kanker payudara, dan AIDS. Kebanyakan masyarakat awam sangat kurang memperhatikan kesehatan, terutama kesehatan jantung. Mereka enggan memeriksakan kesehatan jantungnya karena kurangnya pelayanan terhadap pasien, kurangnya tenaga medis khususnya dokter spesialis jantung serta jam kerja dokter yang terbatas. Sehingga perlunya suatu teknologi yang mampu mengadopsi cara berfikir manusia yaitu teknologi kecerdasan buatan. Sistem pakar merupakan salah satu dari teknologi kecerdasan buatan. Sistem pakar ini dibuat sebagai sarana untuk membantu mendiagnosa dan penatalaksanaan terhadap pasien. Pengembangan sistem ini menggunakan algoritma forward chaining dan certainty factor, dan tools pengembangan sistem yang digunakan adalah UML (Unified Modeling Language), Penelitian ini akan menghasilkan aplikasi sistem pakar untuk mendiagnosa penyakit jantung dengan keluaran berupa kemungkinan penyakit disertai persentasenya. Diharapkan dibuatnya sistem pakar ini akan membantu dan mempercepat kerja dokter jantung dalam mendiagnosa awal penyakit jantung.
\end{abstract}

Kata Kunci-penyakit jantung, forward chaining, Unified Modeling Language, Sistem pakar, Diagnosis 


\section{Pendahuluan}

Perkembangan dunia teknologi telah banyak digunakan di berbagai ilmu guna mempermudah dan membantu dalam pekerjaan sehari hari [5] [6] .

Penyakit jantung menduduki peringkat teratas penyebab kematian dibandingkan stroke, kanker paru-paru, kanker payudara, dan AIDS.[1] Kebanyakan masyarakat awam sangat kurang memperhatikan kesehatan, terutama kesehatan jantung[2]. Mereka enggan memeriksakan kesehatan jantungnya karena kurangnya pelayanan terhadap pasien, kurangnya tenaga medis khususnya dokter spesialis jantung serta jam kerja dokter yang terbatas[3]. Sehingga perlunya suatu teknologi yang mampu mengadopsi cara berfikir manusia yaitu teknologi kecerdasan buatan.

Sistem pakar merupakan program komputer yang dirancang dan dibuat oleh manusia yang dapat meniru proses pemikiran dan pengetahuan dari seorang pakardi suatu bidang dalam menyelesaikan suatu permasalahan[7]. Sistem pakar juga merupakan salah satu dari teknologi kecerdasan buatan[9]. Sistem pakar ini dibuat sebagai sarana untuk membantu mendiagnosa dan penatalaksanaan terhadap pasien.

Dengan adanya aplikasi ini bukan berarti menghilangkan ataupun menggantikan peran dari seorang pakar, ahli dan dokter spesialis jantung di rumah sakit, tetapi dapat lebih memasyarakatkan pengetahuan para pakar / ahli / dokter penyakit jantung melalui aplikasi ini, serta masyarakat dapat mengetahui langsung bagaimana cara mengidentifikasikan jenis penyakit jantung berdasarkan gejala yang dirasakan. Peran dokter masih diperlukan untuk membenarkan serta dilakukannya pemeriksaan lanjutan terhadap penyakit pasien jika diperlukan. Sehingga dengan adanya sistem ini dapat mempermudah dan mempercepat kinerja dokter dalam mendiagnosa awal penyakit jantung yang diderita oleh pasien. Dengan menggunakan sistem pakar diharapkan dapat mempercepat dalam mendiagnosa suatu jenis penyakit jantung sehingga dapat dengan mudah diketahui jenis penyakit tersebut. Selain itu sebagai suatu alternatif solusi untuk mengatasi masalah yang dialami oleh dokter dan petugas kesehatan.

\section{Metode Penelitian}

Dalam Penelitian ini Kami Menggunakan Metode Forward Chaining. Menurut [4] Metode Forward Chaining adalah metode pencarian atau teknik pelacakan kedepan yang dimulai dengan informasi yang ada dan penggabungan rule untuk menghasilkan suatu kesimpulan 
atau tujuan. Metode inferensi runut maju cocok digunakan untuk menangani masalah pengendalian (controlling) dan peramalan (prognosis). Teknik Forward Chaining merupakan teknik yang sering digunakan untuk proses inferensia yang memulai penalarannya dan sekumpulan data menuju kesimpulan yang dapat ditarik. Teknik Forward Chaining yaitu metode penalaran yang bergerak dan IF part menuju THEN part.

Dicontohkan pada tabel 1 di bawah ini terlihat 10 aturan yang tersimpan dalam basis pengetahuan. Fakta awal yang diberikan hanya A \& F (artinya A dan F bernilai benar). Ingin dibuktikan apakah $\mathrm{K}$ bernilai benar (hipotesis : K) ?

Tabel 1. Aturan basis Pengetahuan

Forward Chaining

\begin{tabular}{|c|c|}
\hline Nomor & Aturan \\
\hline R-1 & IF A \& B THEN C \\
\hline R-2 & IF C THEN D \\
\hline R-3 & IF A \& E THEN F \\
\hline R-4 & IF A THEN G \\
\hline R-5 & IF F \& G THEN D \\
\hline R-6 & IF G \& E THEN H \\
\hline R-7 & IF C \& H THEN I \\
\hline R-8 & IF I \& A THEN J \\
\hline R-9 & IF G THEN J \\
\hline R-10 & IF J THEN K \\
\hline
\end{tabular}

Langkah-langkah yang harus dilakukan dalam membuat sistem forward chaining berbasis aturan, yaitu: a. Pendefinisian Masalah

Tahap ini meliputi pemilihan domain masalah dan akusisi pengetahuan.

b. Pendefinisian Data Input

Algoritma forward chaining memerlukan data awal untuk memulai inferensi.

c. Pendefinisian Struktur Pengendalian Data Aplikasi yang kompleks memerlukan premis tambahan untuk membantu mengendalikan pengaktifan suatu aturan.

d. Penulisan Kode Awal

Tahap ini berguna untuk menentukan apakah sistem telah menangkap domain pengetahuan secara efektif dalam struktur aturan yang baik.

e. Pengujian Sistem

Pengujian sistem dilakukan dengan beberapa aturan untuk menguji sejauh mana sistem berjalan dengan benar.

f. Perancangan Antarmuka

Antarmuka adalah salah satu komponen penting dari suatu sistem. Perancangan antarmuka dibuat bersama-sama dengan pembuatan basis pengetahuan.

g. Pengembangan Sistem

Pengembangan sistem meliputi penambahan antarmuka dan pengetahuan sesuai dengan prototipe sistem. 
h. Evaluasi Sistem

Pada tahap ini dilakukan pengujian sistem dengan masalah yang sebenarnya. Jika sistem belum berjalan dengan baik maka akan dilakukan pengembangan kembali.

\section{Hasil dan Pembahasan}

Pada penelitian ini, dibutuhkan data untuk menganalisis kebutuhan yaitu data jenis jenis pada penyakit jantung beserta gejala gejala pada penyakit jantung, dengan adanya ke dua data tersebut kita dapat membuat aturan forward chaining seperti Tabel 4.

Adapun jenis jenis penyakit jantung dapat dilihat pada tabel 2 dibawah ini :

\section{Tabel 2. Jenis Jenis Penyakit} Jantung

\begin{tabular}{|l|l|}
\hline $\begin{array}{c}\text { ID } \\
\text { Penyakit }\end{array}$ & \multicolumn{1}{c|}{ Nama Penyakit } \\
\hline P01 & Penyakit Jantung Koroner \\
\hline P02 & Penyakit Gagal Jantung \\
\hline P03 & Penyakit Jantung Iskemik \\
\hline P04 & Penyakit Katup Jantung \\
\hline P05 & Penyakit Otot Jantung \\
\hline P06 & Penyakit Jantung Hipertensi \\
\hline P07 & Penyakit Kardiomegali \\
\hline
\end{tabular}

Dalam penelitian ini membahas 7 jenis penyakit jantung, dan terlihat Pada tabel 2 tersebut menunjukkan penyakit jantung memiliki 7 jenis penyakit jantung . masing masing jenis penyakit jantung terdapat gejala gejala yang berbeda beda. Sehingga dapat dihimpun semua gejala gejala penyakit jantung dapat dilihat pada tabel 3 dibawah ini.

Table 3. Gejala Gejala Penyakit

\section{Jantung}

\begin{tabular}{|l|l|}
\hline Gejala & Nama Gejala \\
\hline G001 & Nyeri Data \\
\hline G002 & Bahu kiri kerasa tidak enak \\
\hline G003 & Keringat dingin \\
\hline G004 & Sesak nafas \\
\hline G005 & Gangguan pencernaan \\
\hline G006 & Mual \\
\hline G007 & Detak jantung tidak teratur \\
\hline G008 & Pusing \\
\hline G009 & Kaki bengkak \\
\hline G010 & Jantung berdebar debar \\
\hline G011 & Mudah lelah \\
\hline G012 & Nyeri di daerah dada tengah \\
\hline G013 & Mudah berkeringat \\
\hline G014 & Dada mengencang \\
\hline G015 & Pembengkakan pada jantung \\
\hline G016 & Kelainan fungsi hati \\
\hline G017 & Pendarahan dari hidung \\
\hline G018 & Wajah kemerahan \\
\hline G019 & Batuk \\
\hline G020 & Sakit perut \\
\hline G021 & Detak jantung cepat \\
\hline G022 & Nyeri di daerah lengan kiri \\
\hline G023 & Penggung terasa tidak enak \\
\hline G024 & Sakit kepala \\
\hline & \\
\hline
\end{tabular}

Pada tabel 3 diatas menunjukan gejala gejala yang ada pada semua jenis penyakit jantung, terdapat 24 gejala yang dibutuhkan pada penelitian ini. Dengan adanya data penyakit dan data gejala, maka dapat dibuatkan aturan aturan forward chaining, adapun tabel aturan dapat dilihat pada tabel 4 dibawah ini : 
Table 4. Tabel Aturan

\begin{tabular}{|c|c|c|}
\hline No & Penyakit & Aturan \\
\hline 1 & P01 & $\begin{array}{l}\text { IF nyeri dada AND } \\
\text { bahu kiri teraasa tidak } \\
\text { enak AND keringat } \\
\text { dingin AND sesak } \\
\text { nafas AND gangguan } \\
\text { pencernaan } \\
\text { mual AND detak } \\
\text { jantung tak teratur } \\
\text { AND lengan kiri } \\
\text { terasa tak enak AND } \\
\text { punggung terasa tak } \\
\text { enak THEN penyakit } \\
\text { jantung coroner }\end{array}$ \\
\hline 2 & P02 & $\begin{array}{l}\text { IF sesak nafas AND } \\
\text { pembengkakan pada } \\
\text { jantung AND kelainan } \\
\text { fungsi jantung THEN } \\
\text { penyakit } \\
\text { jantung }\end{array}$ \\
\hline 3 & P03 & $\begin{array}{l}\text { IF nyeri di daerah } \\
\text { dada tengah AND } \\
\text { mudah berkeringat } \\
\text { AND } \\
\text { mengencang AND } \\
\text { nyeri di daerah lengan } \\
\text { kiri AND penebalan } \\
\text { tendon Achilles } \\
\text { THEN Penyakit } \\
\text { Jantung Iskemik }\end{array}$ \\
\hline 4 & P04 & $\begin{array}{l}\text { IF mudah lelah AND } \\
\text { jantung berdebar } \\
\text { debar AND nyeri dada } \\
\text { AND sesak nafas } \\
\text { AND batuk AND kaki } \\
\text { bengkak } \\
\text { Penyakit } \\
\text { Jantung }\end{array}$ \\
\hline 5 & P05 & $\begin{array}{l}\text { IF sesak nafas AND } \\
\text { pusing AND kaki } \\
\text { bengkak AND jantung } \\
\text { berdebar debar AND } \\
\text { mudah lelah AND } \\
\text { detak jantung tidak } \\
\text { teratur THEN } \\
\text { Penyakit Otot Jantung } \\
\text { (Kardiomiopati) }\end{array}$ \\
\hline
\end{tabular}

\begin{tabular}{|c|c|c|}
\hline 6 & P06 & $\begin{array}{lr}\text { IF sakit kepala AND } \\
\text { pendarahan } & \text { dari } \\
\text { hidung AND } & \text { pusing } \\
\text { AND } & \text { wajah } \\
\text { kemerahan } & \text { AND } \\
\text { mudah lelaj } & \text { THEN } \\
\text { Penyakit } & \text { Jantung } \\
\text { Hipertensi } & \end{array}$ \\
\hline 7 & P07 & $\begin{array}{lr}\text { IF sakit perut } & \text { AND } \\
\text { detak jantung tak } \\
\text { teratur AND detak } \\
\text { jantung cepat AND } \\
\text { nyeri dada THEN } \\
\text { Penyakit Jantung } \\
\text { Hipertrofik } \\
\text { (Kardiomegali) }\end{array}$ \\
\hline
\end{tabular}

Pada tabel 4 diatas menunjukan aturan aturan forward chaining yang menjadi acuan untuk menghasilkan tabel keputusan, adapun tabel keputusan dapat dilihat pada tabel 5 dibawah ini:

Tabel 5. Tabel Keputusan

\begin{tabular}{|l|l|l|l|l|l|l|l|}
\hline \multirow{2}{*}{ Gejala } & \multicolumn{7}{|c|}{ Hasil Diagnosa } \\
\hline & P01 & P02 & P03 & P04 & P05 & P06 & P07 \\
\hline G001 & Y & & & Y & & & Y \\
\hline G002 & Y & & & & & & \\
\hline G003 & Y & & & & & & \\
\hline G004 & Y & Y & & Y & Y & & \\
\hline G005 & Y & & & & & & \\
\hline G006 & Y & & & & & & \\
\hline G007 & Y & & & & Y & & Y \\
& & & & Y & Y & \\
\hline G009 & & & & Y & Y & & \\
\hline G010 & & & & Y & Y & & \\
\hline G011 & & & & Y & Y & Y & \\
\hline G012 & & & Y & & & & \\
\hline G013 & & & Y & & & & \\
\hline G014 & & & Y & & & & \\
\hline G015 & & Y & & & & & \\
\hline G016 & & Y & & & & & \\
\hline G017 & & & & & & Y & \\
\hline G018 & & & & & & Y & \\
\hline G019 & & & & Y & & & \\
\hline G020 & & & & & & & Y \\
\hline G021 & & & & & & & Y \\
\hline G022 & & & Y & & & & \\
\hline G023 & Y & & & & & & \\
\hline G024 & Y & & & & & & \\
\hline
\end{tabular}


Setelah kita menganalisis kebutuhan, maka dalam penelitian ini kita akan masuk ke perancangan, adapun perancangan dalam penelitian ini adalah perancangan sistem yang digambarkan menggunakan usecase diagram. Adapun diagram use casenya adalah sebagai berikut :

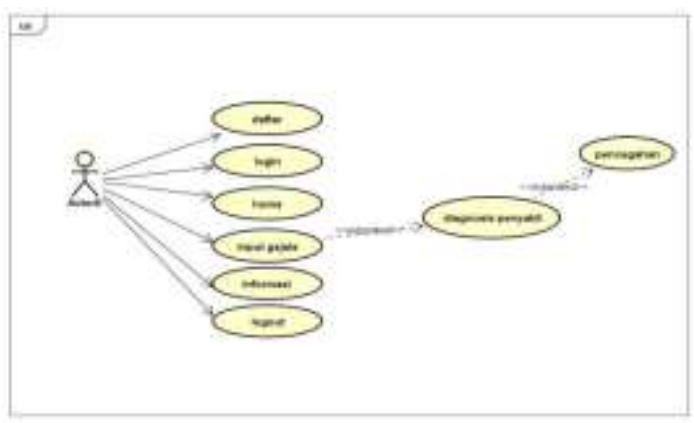

Gambar 2. Use Case Diagram

Pada Gambar 2 diatas menunjukan kebutuhan fungsional yang terdapat didalam sistem, adapun kebutuhannya adalah sistem dapat melakukan fungsi daftar, melakukan login, menampilkan halaman home, dapt menginput gejala, dapat diagnose penyakit, dapt memberikan informasi pencegahan terhadap penyakit yang di diagnose, serta dapat memberikan informasi mengenai 7 penyakit jantung dan dapat melakukan proses logout untuk keluar dari aplikasi.

Setelah merancang sistem, langkah selanjutnya dalam penelitian ini adalah merancang database yaitu dengan membuat Class Diagram adalah sebagai berikut :
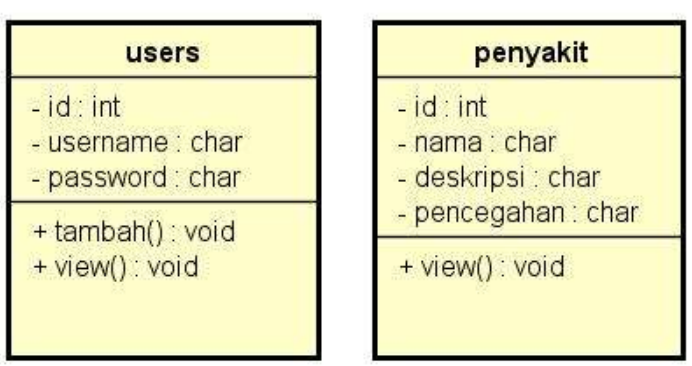

\section{Gambar 3. Class Diagram}

Pada gambar 3 diatas menunjukkan database yang dibuat ada 2 tabel yaitu tabel user dan tabel penyakit. Adapun tabel user menyimpan data semua user yang mendaftar pada sistem aplikasi ini. Adapun tabel penyakit menyimpan semua data penyakit jantung.
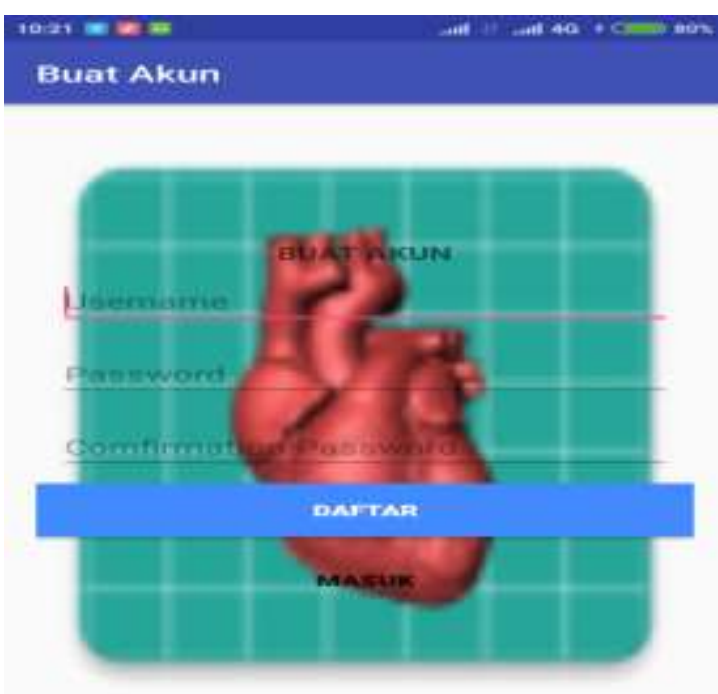

\section{Gambar 4 Tampilan Layar \\ Pendaftaran User.}

Pada gambar 4 merupakan tampilan layar pendaftaran user yang digunakan sebagai syarat untuk dapat mengakses sistem aplikasi ini. 


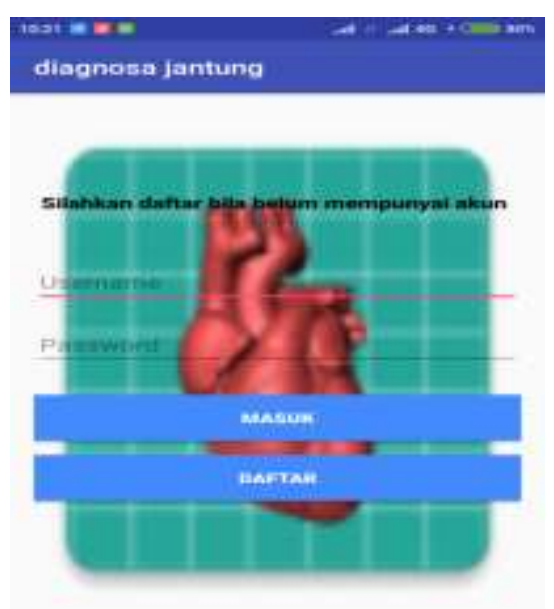

Gambar 5. Tampilan Layar login

Pada gambar 5 merupakan tampilan layar login yang digunakan untuk authentifikasi user sistem aplikasi ini.

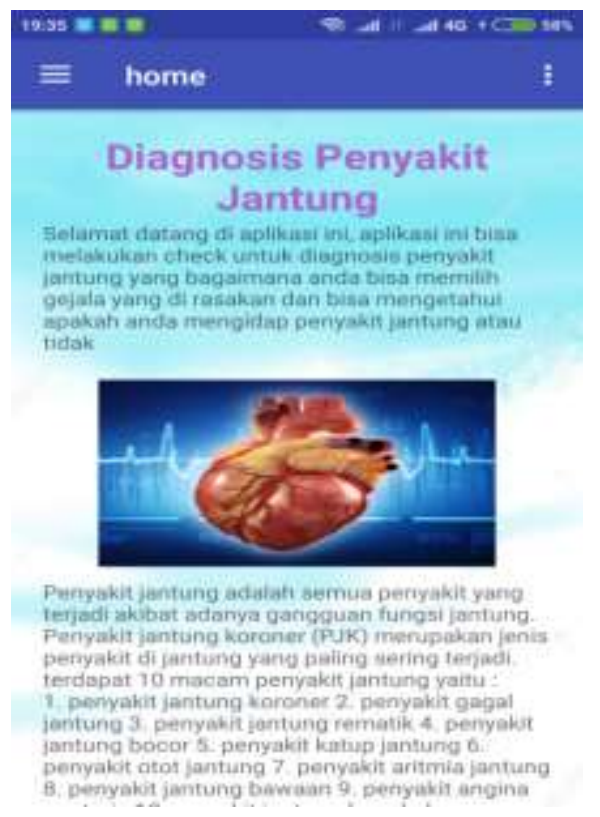

\section{Gambar 6. Tampilan Layar Utama}

Pada gambar 6 merupakan tampilan layar utama pada aplikasi ini setelah kita berhasil masuk ke dalam sistem aplikasi ini.

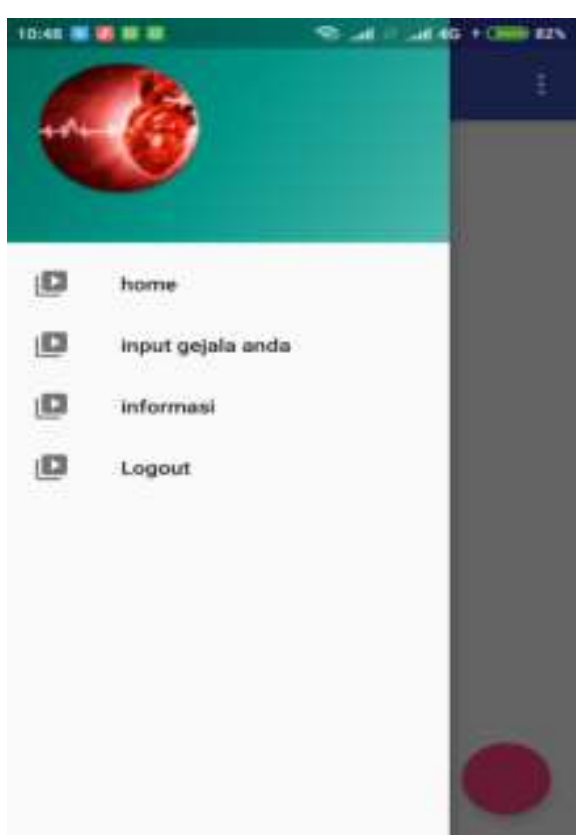

Gambar 7. Tampilan Layar navigasi Pada Gambar 7 diatas merupakan tampilan layar navigasi, yang berisi 4 menu, diantaranya menu home, menu input gejala, menu informasi, serta menu untuk keluar.

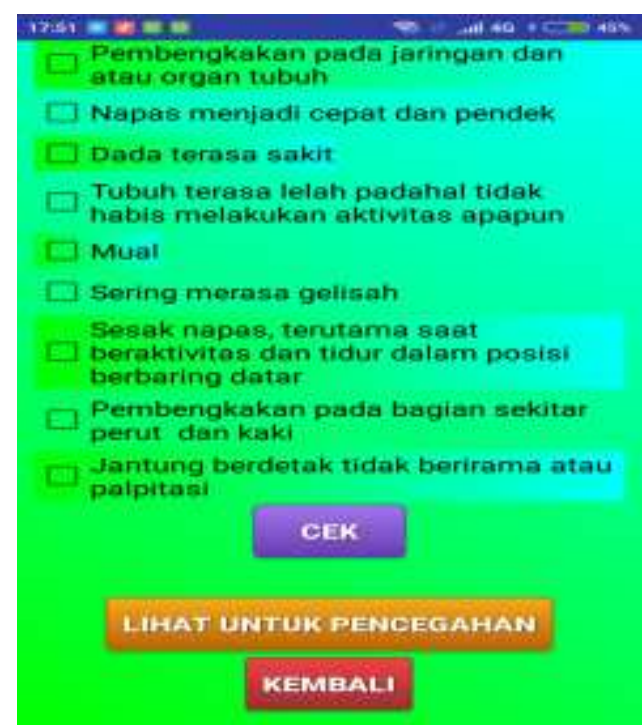

Gambar 8. Tampilan Layar input

$$
\text { gejala }
$$

Pada gambar 8 merupakan tampilan layar input gejala yang dirasakan oleh user, user dapat memilih dan menceklistkan 
gejala gejala yang dirasakan user. Dan juga terdapat tombol cek untuk mendiagnosa penyakit jantung berdasarkan gejala gejala yang sudah diinputkan. Selain itu juga setelah muncul hasil dari diagnosa, dapat melihat untuk pencegahan dari penyakit user yang didiagnosa oleh sistem.

\section{Simpulan}

Penyakit jantung merupakan penyakit yang paling ganas dan dapat menyebabkan kematian. Banyak yang meninggal dikarenakan penderita penyakit jantung. Penyakit jantung dapat dicegah dan juga dapat diobati dengan beberapa car. Dalam penelitian ini telah membahas dan menerapkan suatu teknologi yang mampu mengadopsi cara berfikir manusia yaitu teknologi kecerdasan buatan sebagai sarana untuk membantu mendiagnosa dan memberikan informasi serta pencegahan dari beberapa penyakit jantung.

Teknologi yang dibuat dalam penelitian ini dapat membantu dan mempercepat kerja dokter jantung dalam mendiagnosa awal penyakit jantung, memberikan informasi dan wawasan mengenai 7 penyakit jantung, membantu untuk mendiagnosa penyakit jantung yang diderita, membantu memberikan informasi penanggulangan penyakit yang diderita, serta dapat membantu dokter spesialis jantung yang masih minim.

\section{DAFTAR PUSTAKA}

[1] Raharjo, J S D, Damdan Damiyana, Lioe Steven, 2017, Perancangan Sistem Pakar Diagnosa Penyakit Jantung dengan Metode Forward Chaining Berbasis Android, STMIK Bina Sarana Global

[2] Rachmawati, N., 2014, Sistem Pakar Untuk Mendiagnosa Penyakit Jantung dengan Metode Forward Chaining Berbasis Dekstop, Universitas Muhammadiyah Surakarta, Surakarta

[3] Santoso, L, W \& Agustinus Noertjahyana, Ivan L., 2013, Aplikasi Sistem Pakar Berbasis Web untuk Mendiagnosa Awal Penyakit Jantung, Universitas Kristen Petra, Surabaya

[4] Putri , P A, \& Hindayanti M., 2014, Sistem Pakar untuk Mendiagnosa Penyakit Hati Menggunakan Metode Forward Chaining, Universitas Muhammadiyah Purwokerto, Purwokerto

[5] Lestari, S., \& Diantoro, W. (2018). Metode Case Based Reasonig (CBR) Pada Sistem Diagnosa Penyakit Kulit. Jurnal Informatika, 18(1), 21-34.

[6] Sugihartono, Tri., R Burham I F, 2016, Prototipe Multimedia Pembelajaran Tilawatil Quran Berbasis Android Pada TPA XYZ, 
Jurnal TI Atma Luhur, STMIK Atma

Luhur, Pangkalpinang

[7] Sugihartono, Tri., 2018, Implementasi

Sistem Pendukung Keputusan

Penerima Bantuan Rumah Tidak

Layak Huni Berbasis Web, Jurnal

Sisfokom, STMIK Atma Luhur,

Pangkalpinang

[8] Giarratano\& Riley, 2014, Expert Systems: Principles and

Programming. Papperback

[9] McPhee, Stephen J, 2013, Current

Medical Diagnosis \& Treatment.

United States : The McGraw-Hill

Companies, Inc

[10] Marimin, 2014, Teori dan Aplikasi

Sistem Pakar Dalam Teknologi

Manajerial, Bogor : IPB Press 